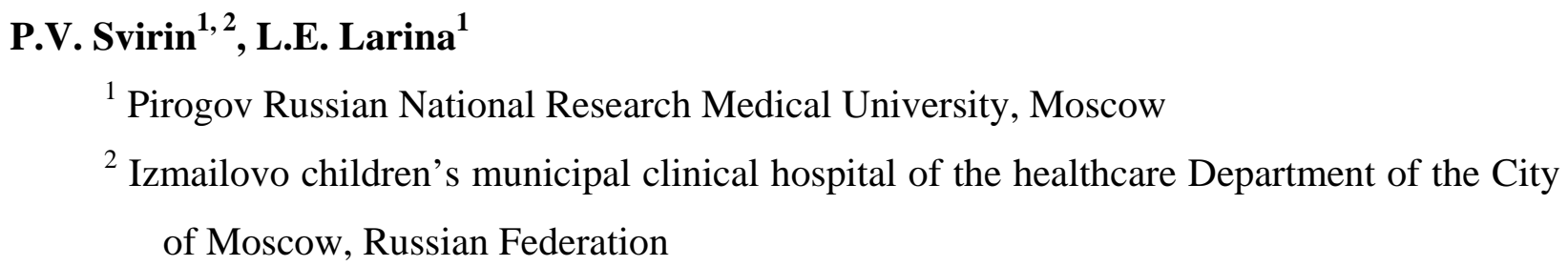

${ }^{1}$ Pirogov Russian National Research Medical University, Moscow

${ }^{2}$ Izmailovo children's municipal clinical hospital of the healthcare Department of the City of Moscow, Russian Federation

\title{
HEMORRHAGE EXPRESS-DIAGNOSTICS AND THERAPY IN CHILDREN 0-6 MONTHS OF AGE
}

Author affiliation:

Pavel Vyacheslavovich Svirin, teaching assistant at the oncology and hematology department of the pediatric faculty at the Pirogov RNRMU

Address: 48, Verkhnyaya Pervomaiskaya Str., Moscow, 105077, tel.: +7 (495) 465-60-83

Articles received: 17.12.2012 accepted for publication: 24.04.2013.

Hemorrhagic conditions are associated with severe health problems and an increase in mortality rate among children. Quick and adequate reaction of a doctor who was the first to appear beside such a patient is necessary to save the child's life; mistakes may lead to severe complications, including fatal outcome. The article formulates methodological recommendations on diagnosing and rendering help to children of the first months of age with developing hemorrhagic manifestations in the environment of neonatal and newborn centers taking into account their laboratorial and therapeutic capabilities.

Keywords: hemostasis, hemorrhagic conditions, causes, diagnostics, treatment, children.

\section{INTRODUCTION}

Hemorrhagic conditions in children of the first months of life may be a serious problem both for a patient and for a doctor. The experience shows that many specialists encountering hemorrhagic manifestations tend to make mistakes which may influence patients' life quality, and sometimes may lead to severe and even fatal consequences. We encounter cases of both over- and under-diagnostics and thus with the prescription of inadequate therapy. It is obvious that many tests which allow verifying diagnosis are available only at specific laboratories. That is why in this article we made an attempt to formulate methodological recommendations on diagnostics and help rendering to children of the first months of life developing hemorrhagic manifestations in the conditions of neonatal and newborn centers given their laboratorial and therapeutic capabilities. At the same time, we deem right using modern drugs to conduct replacement therapy even in the departments that do not specialize in treating blood diseases. As far as the article was written to help pediatricians, we did not describe diagnostic and medical measures requiring hematologist's prescription or participation. 
In this article we restricted the treatment group to children of 0-6 months of age, as the hemostatic system is developing in this period. Its functional characteristics may be significantly different from hemostatic system of older children. Data on the specific laboratory parameters of hemostatic system are given in reference literature; reference values for each age group should be given by a laboratory. There is no such information in this article.

\section{MAIN DEFINITIONS}

Hemostasis is a bodily function aimed at, on the one hand, preserving liquid state of blood in the undamaged blood channel, on the other - maintaining hemorrhage control and preventing physiologically significant blood loss in case of the damaged blood vessel.

The most important functional notion of hemostasis is hemostatic balance (HB). HB is a result of hemostatic system's work. The main functions given in the definition of hemostasis are realized in case of normal HB. Development of thromboses or hemorrhagic diathesis means HB is upset [1].

The main hemostatic system's components, interconnection of which is maintained by HB, are vascular wall, platelets and blood plasma proteins.

HB disorder may have hemorrhagic, thrombotic or mixed character. In this article we stop at hemorrhagic HB disorders or hemorrhagic conditions (HC). HC result from a hereditary or acquired disorder of one or several hemostatic system's components, which is why it is necessary to determine which component or components were deranged when identifying $\mathrm{HC}$ signs.

\section{PATHOLOGY RANGE}

The most frequent causes of hemorrhagic disorders in children of 0-6 months of age are given below.

Vascular hemostasis disorder:

- hypoxic and hypoxic-traumatic disorders - gastrointestinal tract, intraventricular and differently localized hemorrhages are possible;

- vascular tumors - thrombocytopeniae and hypofibrinogenemiae are possible;

- inflammation of Meckel's diverticulum - gastrointestinal tract hemorrhages are possible;

- $\quad$ aneurism ruptures (intracranial hematomas).

Thrombocyte hemostasis disorder:

- $\quad$ neonatal thrombocytopeniae; 
- $\quad$ thrombocytopathies.

Plasma hemostasis disorder:

- $\quad$ hemorrhagic vitamin-K-dependent coagulopathy (hemorrhagic disease of the newborn);

- $\quad$ hemophilia;

- $\quad$ other hemorrhagic coagulopathies.

\section{DISSEMINATED INTRAVASCULAR COAGULATION (DIC)}

\section{Clinical diagnostics}

It is necessary to determine the presence of at least one of the following signs for clinical diagnostics of HC in children of 0-6 months of age:

- lack of hemorrhagic manifestation's correspondence to the traumatic influence's character and severity;

- $\quad$ spontaneous hemorrhagic manifestations.

It is necessary to take into account the fact that there should be no hemorrhagic manifestations in children of 0-6 months of age. Traumas in them are only caused by incorrect manipulations of the people around. The early puerperal period is the only exclusion. Thus, any hemorrhagic manifestation in children of 0-6 months of age should be seen as the presence of HC. Misinterpretation is not rare on this stage. We may assume that the child was handled roughly only if the test results are normal. There have been cases in our practice where underestimation of the first hemorrhagic manifestations led to severe and even fatal consequences.

\section{Laboratory diagnostics}

Clinical manifestations of many hemorrhagic conditions are similar and do not usually allow diagnosing the disease's form. It is necessary to conduct laboratory tests in order to select therapy. There are 2 main ways to solve most emergency issues: to use standard screening tests or to use "point of care" analysis techniques.

\section{Screening tests}

In most cases, the 6 following tests are necessary and sufficient [2, 3]:

1. Activated partial thromboplastin time (APTT).

2. Prothrombin time (PT).

3. Thrombin time (TT).

4. Fibrinogen concentration. 
5. Hemorrhage time (HT).

6. Amount of platelets.

The time necessary to fulfill these tests is, as a rule, 40-120 minutes. Tb. 1 gives a differential-diagnostic algorithm using screening tests.

Hemorrhagic disease of the newborn (HDN) has a similar laboratory presentation to the isolated deficiency of factors II, V and X. Long-lasting effect of using vitamin K drugs may serve as a differential-diagnostic criterion of HDN.

It is not possible to differentiate hemophilia A and B and deficiency of factors XI and XII relying on the screening tests' results. At the same time, factor XII deficiency does not lead to spontaneous hemorrhagic manifestations and constitutes a threat only in case of surgical treatment or severe injuries. Factor XI deficiency occurs, as a rule, in an ethnic group of the Askhenazi Jews. In the other ethnic groups it occurs sporadically, with a rate less than $1: 1,000,000$.

It should be noted that joint combinations are possible in exceptional cases.

\section{"Point of care" technologies [4, 5]}

At present, there are technologies which allow quickly obtaining laboratory data which influence the decision-making of therapy at the bedside. These approaches are called "point of care”. The equipment which allows obtaining results of several tests (PT, activated coagulation time using kaolin etc.) within a few minutes is available in Russia; however, there is no such device yet that would fulfill differential diagnostics of all hemorrhagic diathesis causes. However, using the available equipment, given clinical manifestations (hemorrhage time extension signs), amount of platelets, data on the frequency of different conditions and family disease anamnesis may allow conjecturing diagnosis and conducting adequate primary therapy. Time saved by the "point of care” technology may save patient's health or life.

Apart from the standard coagulologic tests, there is a possibility of examining thromboelastogram. Result generation time does not exceed 15 minutes for these tests.

Thromboelastogram (TEG) is one of the first methods of examining hemostatic system. Modern thromboelastometers allow analyzing TEG with coagulation activation using the same ways as when examining a coagulogram (APTT and PT); analyzing hemostatic condition given the heparin action; blocking excessive fibrinolysis etc. TEG analysis allows differentiating between coagulopathies caused by the reduction in external and internal coagulation factor activity and thrombocytic component deficiency and also revealing heparin in the sample and hyperfibrinolysis. 
"Point of care" tests' data should be interpreted according to the principles given above (see tb. 1).

As far as the possible need in qualifying tests is high, part of the patient's plasma obtained before the treatment should be frozen at the temperature of $-30^{\circ} \mathrm{C}$ or less .

\section{THERAPEUTIC MEASURES}

The first therapeutic measure for a patient of 0-6 months of age admitted to an inpatient department with hemorrhagic symptoms should be the administration of a vitamin $\mathrm{K}$ drug (Vicasol, Conakion). It may be done before diagnostic measures are undertaken. This therapy will allow bringing recovery closer in patients with vitamin K deficiency and will not harm other patients.

The main therapeutic measure at coagulopathies is the replacement therapy using blood coagulation drugs. Tb. 2 lists drugs for replacement therapy at hemorrhagic coagulopathies.

Drugs given in tb. 2 may be distinguished into 2 groups:

1) crude, non-viricidal - cryoprecipitate (Cryo) and fresh frozen plasma (FFP);

2) pure, viricidal - concentrates of blood coagulation factors. The latter may in their turn by distinguished into 2 groups:

a) non-activated drugs are used for replacement therapy;

b) activated drugs are used for "bypass therapy" in cases when replacement therapy is for some reason impossible. As far as these drugs have high thrombogenicity, indications to their use are restricted. For the activated drug of factors II, VII, IX and X - inhibitory hemophilia, for the activated factor VII - inhibitory hemophilia A and B, Glanzmann’s disease, factor VII deficiency.

\section{Main principles of replacement therapy conduct using blood coagulation factors.}

- In the first place - using pure viricidal drugs taking into account their composition. Fresh frozen plasma is, as a rule, ineffective, even when used properly.

- Administering the sufficient dose with sufficient speed. Slow administration or insufficient dose administration reduces therapy efficiency considerably.

- In case differential diagnostics is impossible, e.g. at the isolated APTT extension, simultaneous administration of several drugs may be used, e.g. concentrates of factors VIII and IX.

- In case FFP or Cryo drugs are to be used, the preparations are defrosted for 5-10 minutes at the temperature of $38-40^{\circ} \mathrm{C}$ and administered just after defrosting as fast as possible (Cryo - stream introduction, FFP - stream or fast drop-by-drop introduction). The necessary dose of fresh frozen plasma must be introduced within 1 hour. 
Mixed extension of APTT and PT at normal indices of TT and fibrinogen. It is often accompanied by hemorrhage time extension. The most possible diagnosis - hemorrhagic disease of the newborn. We have most often been encountering HDN manifestations in children of ca. 1 month of age. Predominant majority of the suffering children consists of those who are fed exclusively naturally. The main manifestations are bruises; hemorrhage from blood sampling and injection sites and mucous tunics; intracranial hemorrhage. The latter take a much severer course than most other coagulopathies. Mortality from intracranial hemorrhage is ca. $40 \%$; the survived often suffer from severe neurologic impairment, which is why it is extremely important to render hemostatic help as soon as possible.

Vitamin K must be administered intramuscularly, intravenously or orally as soon as possible. Single dose of Vicasol is $4 \mathrm{mg}$ (prescribed as $1 / 4$ of a tablet or $0.2-0.4 \mathrm{ml}$ of solution), single dose of Conakion - 1mg.

Indications to replacement therapy with blood preparations are:

- bleeding or hemorrhage (including suspected hemorrhage);

- upcoming invasive manipulation or operation;

- convulsions;

- child's unmotivated or intense anxiety;

- condition severity due to the intercurrent disease.

An optimal preparation for replacement therapy is the non-activated concentrate of prothrombin complex factors. Single dose is 50-10 IU/kg. As a rule, singular drug's administration with vitamin $\mathrm{K}$ results in recovery.

Hemostasis is checked 15-30 minutes after blood preparations were introduced; therapy is evaluated and corrected. If hemostasis has normalized, it is revalidated in 12-24 hours.

If the sufficient dose of prothrombin complex factors' concentrate does not lead to an adequate laboratory effect, it is possible that the patient has consumption syndrome due to DIC, hemangiomae, hemorrhage or infection. Similar laboratorial and clinical presentation is possible in case of hepatopathies.

Repeated extension of APTT or PT in 12-24 hours to the indices lower than the age norm indicates either the remaining vitamin K deficiency or hereditary deficiency of one of coagulation factors - II, V or X. In case of factor V deficiency, administration of prothrombin complex factors' drugs may be ineffective and fresh frozen plasma will be required (10$20 \mathrm{ml} / \mathrm{kg})$.

Differential diagnostics requires examining activity of the prothrombin complex factors from the blood sample taken before the replacement therapy (as was stated above). 
Duration and doses for replacement therapy are selected by a hematologist in case of hereditary deficiency diagnostics. All patients having suffered deficiency of prothrombin complex factors should repeatedly be consulted and examined by a hematologist after reaching 6-12 months of age.

Isolated APTT extension. The most probable diagnosis in case of hemorrhagic manifestations is hemophilia A (morbidity - 1:10,000 newborn boys), rarer - hemophilia B (1:80,000 newborn boys). Girls suffer from hemophilia extremely rarely, patients with factor XI deficiency are also found only in exceptional cases. It is possible to differentiate hemophilia A (blood coagulation factor VIII insufficiency) and hemophilia B (blood coagulation factor IX insufficiency) analyzing activity of these factors in a sample taken before the replacement therapy.

Intravenous introduction of factor VIII or IX concentrate is indicated for hemostatic therapy. Mixed administration of these preparations is possible if there is no information on the type of hemophilia. The dose of each per 1 administration is 50-100 IU/kg. The APTT test should be done again 15-30 minutes after the administration: APTT normalizes when the replacement therapy is conducted correctly.

Indications for the replacement therapy:

- bleeding or hemorrhage;

- upcoming operative treatment or invasive procedure;

- neurologic manifestations, including convulsions, unmotivated or intense anxiety.

In case the laboratory response to the replacement therapy is normal, the repeated introduction may be needed in 12-24 hours. Extended APTT preservation is usually associated with deficiency in factors XI and XII. The deficiency is corrected by fresh frozen plasma (10$30 \mathrm{ml} / \mathrm{kg}$ ). Isolated extended APTT detection requires immediate hematologist's consultation in order to establish diagnosis and select therapy.

APTT extension together with HT extension. The most probable diagnosis is Von Willebrand disease. Replacement therapy is conducted according to the same indications as in case of hemophilia using factor VIII preparations containing Willebrand factor. Dosage and frequency are also the same.

Combine extension of APTT, PT and TT and fibrinogen reduction. Develops in several conditions. Hepatic protein-synthetic malfunction does not usually lead to the platelet level reduction. This allows differentiating this state from DIC and other consumption syndromes at which the platelet level reduction is noted.

In several cases it is difficult to differentiate hepatic protein-synthetic malfunction from hereditary fibrinogen deficiency. The problem is, considerable reduction in fibrinogen makes it 
impossible to determine TT, APTT and PT. It is necessary to analyze blood coagulation factors' activity in a sample taken before the replacement therapy in order to conduct differential diagnostics.

Laboratory data and clinical manifestations may be of additional diagnostic information. Hepatic protein-synthetic malfunction is only rarely accompanied by intense hemorrhagic symptoms, while hypofibrinogenemia may be manifested with prolonged hemorrhage from umbilical and other wounds, propensity to bruises and hematomas, bleeding from injection and blood sampling sites.

The replacement therapy at these conditions requires complex approach. Only fresh frozen plasma is used at DIC. Daily dosage - 15-30ml/kg OD-TID. Cryo and blood coagulation factors' concentrates are used only when the patient's life prognosis is determined only by hemorrhage. In these situations it is allowed to use Cryo and prothrombin complex factors' concentrate. It is possible to use activated preparation in case the former are not sufficiently effective to save life. It should be noted that application of procoagulants at DIC aggravates multiple organ failure.

Apart from FFP it is indicated to introduce heparin in preventive doses (50-150IU/kg per day as continuous infusion), rheological and etiotropic therapy.

Cryo therapy $(5-10 \mathrm{ml} / \mathrm{kg})$ controlled by screening tests is indicated in case of hemorrhagic manifestations in newborns with fibrinogen deficiency, combined extension of APTT, PT and TT and fibrinogen reduction. It is possible to administer prothrombin complex factors' concentrate after the fibrinogen level normalizes and hemisyndrome remains. It is dangerous to use activated preparations in patients with hepatic malfunction as not only procoagulants, but also blood coagulation inhibitors are often reduced in children of 0-6 months of age; this significantly increases risk of thrombosis.

Establishing exact diagnosis, duration and doses of replacement therapy requires hematologist's expertise.

Isolated PT extension indicates blood coagulation factor VII activity deficiency. Hemorrhagic manifestations at this condition rarely develop before 1 year of age. Replacement therapy is conducted by the non-activated factor VII or prothrombin complex factors' concentrate (30-100 IU/kg OD-TID). It is possible to use Eptacog alfa activated (activated recombinant factor VII) (single dose $-30 \mathrm{mcg} / \mathrm{kg}$ ). Detection of such patients requires an immediate hematologist's consultation.

Isolated platelet level reduction. Neonatal thrombocytopeniae - one of the frequent and dangerous causes of hemorrhagic manifestations. Thrombocytopeniae in neonatality and at the 
age of 0-6 months may be of immune and non-immune etiology. Urgent hematologist's consultation is necessary to conduct diagnostics and select therapy tactics.

Detection of neonatal thrombocytopenia requires emergency measures aimed at preventing intracranial hemorrhage and other threatening hemorrhages. Intravenous immunoglobulin $\mathrm{G}$ administration (single dose $-1 \mathrm{~g} / \mathrm{kg}$ ) is required. Course therapeutic dose is 2$3 g / \mathrm{kg}$.

Platelet concentrate replacement therapy is indicated only in case of threatening hemorrhages in the setting of imminent thrombocytopenia. One platelet concentrate dose is administered intravenously drop-by drop given that thrombocytopenia may be case by group or rhesus incompatibility. Conditions of storage and administration require the drug's constant stirring.

Thus, analysis of clinical manifestations and screening tests' results will allow rendering emergency help to a child of 0-6 months of age at hemorrhagic conditions before consulting a hematologist.

\section{REFERENCES}

1. Dolgov V.V., Svirin P.V. Laboratornaya diagnostika narushenii gemostaza [Laboratory Diagnosis of Hemostatic Dsorders]. Tver, «Izdatel'stvo «Triada», LLC, 2005.

2. Letagen S. Gemostaz i gemorragicheskie zabolevaniya. Per. s angl [Hemostasis and Hemorrhagic Disease. Translated from English]. Moscow, Air-Art, 2004.

3. Colman R. W., Hirsh J., Marder V. J., Clowes A., George J. N. Hemostasis and thrombosis: basic principles and clinical practice. 4th edit. Philadelphia, USA, 2001.

4. Kitchen D. P., Kitchen S. et al. Point of Care INR testing devices: performance of the Roche CoaguChek XS and XS Plus in the UK NEQAS BC external quality assessment programme for healthcare professionals: four years' experience. J Clin Pathol. 2012; 65 (12): 1119-23.

5. Weber C. F., Zacharowski K. Perioperative point of care coagulation testing. Dtsch Arztebl Int. 2012; 109 (20): 369-75.

Table 1. Differential diagnostics of main causes of hemorrhagic conditions

\begin{tabular}{|l|c|c|c|c|c|c|}
\hline \multicolumn{1}{|c|}{ Conditions } & $\begin{array}{c}\text { Activated } \\
\text { partial } \\
\text { thromboplastin } \\
\text { time }\end{array}$ & $\begin{array}{c}\text { Prothrombin } \\
\text { time }\end{array}$ & $\begin{array}{c}\text { Thrombin } \\
\text { time }\end{array}$ & Fibrinogen & $\begin{array}{c}\text { Amount } \\
\text { of } \\
\text { platelets }\end{array}$ & $\begin{array}{c}\text { Hemorrhage } \\
\text { time }\end{array}$ \\
\hline $\begin{array}{l}\text { Hemorrhagic disease } \\
\text { of the newborn }\end{array}$ & $\mathrm{E}$ & $\mathrm{E}$ & $\mathrm{N}$ & $\mathrm{N}$ & $\mathrm{N}$ & $\mathrm{E}$ \\
Hemophilia & $\mathrm{E}$ & $\mathrm{N}$ & $\mathrm{N}$ & $\mathrm{N}$ & $\mathrm{N}$ & $\mathrm{N}$ \\
\hline
\end{tabular}




\begin{tabular}{|l|c|c|c|c|c|c|}
\hline $\begin{array}{l}\text { Disseminated } \\
\text { intravascular } \\
\text { coagulation }\end{array}$ & $\mathrm{E}$ & $\mathrm{E}$ & $\mathrm{E}$ & $\mathrm{R}$ & $\mathrm{R}$ & $\mathrm{E}$ \\
\hline Thrombocytopenia & $\mathrm{N}$ & $\mathrm{N}$ & $\mathrm{N}$ & $\mathrm{N}$ & $\mathrm{R}^{\#}$ & $\mathrm{E}$ \\
\hline $\begin{array}{l}\text { Hepatic protein- } \\
\text { synthetic } \\
\text { malfunction*** }\end{array}$ & $\mathrm{E} / \mathrm{N}$ & $\mathrm{E} / \mathrm{N}$ & $\mathrm{E} / \mathrm{N}$ & $\mathrm{R} / \mathrm{N}$ & $\mathrm{N} / \mathrm{R}$ & $\mathrm{N}$ \\
\hline $\begin{array}{l}\text { Fibrinogen disorders* } \\
\text { Heparin in sample }\end{array}$ & $\mathrm{E}$ (rarely N) & $\mathrm{E}$ (rarely N) & $\mathrm{E}$ & $\mathrm{N}$ & $\mathrm{N}$ & $\mathrm{N}$ \\
\hline $\begin{array}{l}\text { Deficiency of factor } \\
\text { VII* }\end{array}$ & $\mathrm{N}$ & $\mathrm{E}$ & $\mathrm{N}$ & $\mathrm{N}$ & $\mathrm{N}$ & $\mathrm{N} / \mathrm{E}$ \\
\hline $\begin{array}{l}\text { Deficiency of factors } \\
\text { V, X and II* }\end{array}$ & $\mathrm{E}$ & $\mathrm{E}$ & $\mathrm{N}$ & $\mathrm{N}$ & $\mathrm{N}$ & $\mathrm{N} / \mathrm{E}$ \\
\hline $\begin{array}{l}\text { Deficiency of factors } \\
\text { XI* and XII** }\end{array}$ & $\mathrm{E}$ & $\mathrm{N}$ & $\mathrm{N}$ & $\mathrm{N}$ & $\mathrm{N}$ & $\mathrm{N}$ \\
\hline $\begin{array}{l}\text { Thrombocytopathies* } \\
\text { Von Willebrand } \\
\text { disease vascular }\end{array}$ & $\mathrm{N}$ & $\mathrm{N}$ & $\mathrm{N}$ & $\mathrm{N}$ & $\mathrm{N}$ or R & $\mathrm{E}$ \\
\hline $\begin{array}{l}\text { Deficiency of factor } \\
\text { XIII, } \\
\text { hemostasis disorders }\end{array}$ & $\mathrm{N}$ & $\mathrm{N}$ & $\mathrm{N}$ & $\begin{array}{c}\text { (rarely } \\
\mathrm{N}\end{array}$ & $\mathrm{E}$ (rarely N) \\
\hline
\end{tabular}

Note. * - rare conditions (sum frequency does not exceed 1:100,000); ** - does not lead to spontaneous hemorrhagic manifestations; *** - changes depend on the primary disease’s severity; it is necessary to take into account results of liver function tests. ${ }^{\#}$ - less than $100 \times 10^{9} /$. $\mathrm{E}$ - extended, $\mathrm{R}$ - reduced, $\mathrm{N}$ - norm.

Table 2. Drugs for replacement therapy at coagulopathies

\begin{tabular}{|c|c|c|c|c|}
\hline Drug group & $\begin{array}{c}\text { Measurement } \\
\text { units }\end{array}$ & $\begin{array}{c}\text { Normal } \\
\text { activity }\end{array}$ & $\begin{array}{c}\text { Effective dose } \\
\text { (in case there is } \\
\text { no data on } \\
\text { activity) }\end{array}$ & $\begin{array}{c}\text { Dose calculation, } \\
\text { application peculiarities }\end{array}$ \\
\hline $\begin{array}{c}\text { Fresh frozen } \\
\text { plasma }\end{array}$ & $\mathrm{ml}$ & - & & Ineffective drug \\
\hline $\begin{array}{c}\text { Factor VIII (factor } \\
\text { VIII with }\end{array}$ & IU & $50-$ & $\begin{array}{c}50-100 \mathrm{IU} / \mathrm{kg} \text { at } \\
\text { a time }\end{array}$ & $\begin{array}{c}1 \mathrm{IU} / \mathrm{kg} \text { increases activity } \\
\text { in blood by 1-2\% (0.01- }\end{array}$ \\
\hline
\end{tabular}




\begin{tabular}{|c|c|c|c|c|}
\hline Willebrand factor) & & & & 0.02 IU per ml) \\
\hline Factor IX & IU & $\begin{array}{c}50- \\
150 \%\end{array}$ & $\begin{array}{c}\text { 50-100 IU/kg at } \\
\text { a time }\end{array}$ & $\begin{array}{c}1 \mathrm{IU} / \mathrm{kg} \text { increases activity } \\
\text { in blood by } 1 \%(0.01 \mathrm{IU} \\
\text { per ml) }\end{array}$ \\
\hline $\begin{array}{c}\text { Factors IX, II, VII, } \\
\text { X }\end{array}$ & IU & $\begin{array}{c}50- \\
150 \%\end{array}$ & $\begin{array}{c}50-100 \mathrm{IU} / \mathrm{kg} \text { at } \\
\text { a time }\end{array}$ & $\begin{array}{c}1 \mathrm{IU} / \mathrm{kg} \text { increases activity } \\
\text { in blood by } 1 \%(0.01 \mathrm{IU} \\
\text { per ml) }\end{array}$ \\
\hline $\begin{array}{l}\text { Factors IX, II, VII, } \\
\text { X (activated drug) }\end{array}$ & IU & & $\begin{array}{c}\text { 50-100 IU/kg at } \\
\text { a time }\end{array}$ & $\begin{array}{c}\text { “Bypass" } \\
\text { THROMBOGENIC drug! } \\
\text { Restricted indications } \\
\text { (inhibitory hemophilia A } \\
\text { form) }\end{array}$ \\
\hline Factor VII & IU & $\begin{array}{c}50- \\
150 \%\end{array}$ & $\begin{array}{c}50-100 \mathrm{IU} / \mathrm{kg} \text { at } \\
\text { a time }\end{array}$ & $\begin{array}{c}1 \mathrm{IU} / \mathrm{kg} \text { increases activity } \\
\text { in blood by } 1 \%(0.01 \mathrm{IU} \\
\text { per ml) }\end{array}$ \\
\hline $\begin{array}{c}\text { Factor VII } \\
\text { (activated drug) }\end{array}$ & mcg & & $\begin{array}{c}\text { 90-120mcg/kh } \\
\text { once in } 2-4 \\
\text { hours or } \\
270 \mathrm{mcg} / \mathrm{kg} \text { once } \\
\text { in } 8-12 \text { hours }\end{array}$ & $\begin{array}{c}\text { “Bypass” } \\
\text { THROMBOGENIC drug! } \\
\text { Restricted indications }\end{array}$ \\
\hline $\begin{array}{l}\text { Cryoprecipitate } \\
\text { (fibrinogen, } \\
\text { factors VIII, XIII) }\end{array}$ & Dose & & $\begin{array}{c}1 \text { dose per } 10 \mathrm{~kg} \\
\text { at a time }\end{array}$ & \\
\hline
\end{tabular}

